Editorial

\title{
A study on clinico-etiological profile of chronic liver disease in children between 1 year to 14 years of age
}

\author{
Behera A. ${ }^{1}$, Murmu M.C. ${ }^{2}$ \\ ${ }^{1}$ Dr. Aarti Behera, Associate Professor, ${ }^{2}$ Dr. Mangal Charan Murmu, Associate Professor, both authors are affiliated with \\ Department of Paediatrics, S.C.B. Medical College \& Hospital, Cuttack, Odisha, India.
}

Corresponding Author: Dr. Mangal Charan Murmu, Associate Professor, Department of Paediatrics, S.C.B. Medical College \& Hospital, Cuttack, Odisha, India, Email: mangal74murmu@yahoo.co.in

\begin{abstract}
Introduction: Chronic liver diseases (CLD) account for 1 to 5\% of paediatric ward admissions and upto $20 \%$ of ward mortality in our country. Now a day Indian childhood cirrhosis is a rarity, whereas diseases likechronic hepatitis, Wilsons disease and biliary atresia are diagnosed with increasing frequency and therefore became relatively important forms of paediatric liver disease. Methodology: The study was done to determine the clinico-etiological profile of chronic liver disease in children 1 year to 14 years. This is a prospective case-controlled study done over a period of two years. Various clinical, biochemical and radiographic parameters pertaining to chronic liver disease were studied. Results: About40 cases were studied. CLD was found to be prevalent in 5-10 years of age group. Male were more affected than female. Jaundice was the most common presenting feature. Hepatomegaly, Ascitis, Splenomegaly were thecommonest presenting signs.Conclusion: CLD is not uncommon condition in children. It constitutes $18.34 \%$ of the patients of the with liver disease in our region. Wilson's disease was the most common aetiology apart from idiopathic which constitute $52.5 \%$ of the cause.
\end{abstract}

Keywords: Liver Diseases, Biliary Atresia,Non-alcoholic fatty liver disease (NAFLD), Children

\section{Introduction}

Chronic liver disease refers to a wide spectrum of disorders characterizedby ongoing liver damage with a potential for progression to cirrhosis or end stage liver disease [1]. CLD implies long standing disease (usually more than 3 to 6 months), leading to various manifestations and complications of liver cell failure. Unlike in adults, long duration of the disease should not be considered as a mandatory aspect of definition of CLD in the children, as progressive irreversible changes can occur in the children, even with symptoms as short as one week [2].

There is emergence of relatively newer liver disorders in children like NAFLD (non-alcoholic fatty liver disease) that were rare in our subcontinent especially in children. There is therefore a continuing need for studies on various aspects of liver diseases in different communitiesand environments [3]. Acute and Chronicliver disease constitute the majority of liver disorders in children. The etiologic profile of CLD also shows

Manuscript received: $30^{\text {th }}$ December 2017

Reviewed: $9^{\text {th }}$ January 2018

Author Corrected: $18^{\text {th }}$ January 2018

Accepted for Publication: $24^{\text {th }}$ January 2018 geographical variation. Hepatitis virus is leading cause of CLD in South East Asia, Middle East and some of other Asian countries. It is predominantly due to high prevalence of hepatitis in general population in these countries.Some of the biliary disorders such as Biliary Artesia present as CLD in regions where diagnosis is delayed beyond twelve weeks. Such children often present with cirrhosis and portal hypertension. Likewise, in some regions of world where oriental cholangiohepatitis $(\mathrm{OCH})$ is endemic can cause secondary biliary cirrhosis, portal hypertension in children if left untreated [4]. The profile of metabolic diseases producing chronic liver disease has not been well documented from developing countries because of lack of diagnostic facilitiesin these regions.

Therefore, the metabolic diseases causing chronic liver disease do not figure well in the studies reported from these underdeveloped countries. The incidence of Indian childhood cirrhosishas come down [5]. The parasitic liver diseases such as hydatid cyst, schistosomiasis continue to form a part of liver disease in endemic states [6]. In recent yearsnon-alcoholic steatohepatitis 
(NASH) has been described as a commoncause of liver disease in children which is related to obesity, hyperinsulinemia, insulin resistance, and liver cell injury from free fatty acid toxicity or oxidant stress. Overall prevalence of fatty liver in children is $2.6-12.5 \%$ [7].

In this study the pattern of CLD in children attending our hospital were analysed as there is dearth of information on this.

\section{Objectives}

The aim of the study is to determine the etiological profile, clinical manifestations, different haematological \& biochemical abnormalities and its complicationsof chronic liver disease in children aged 1 year to 14 years.

\section{Material}

This is a direct observation study. The study was conducted in the Department of Pediatrics, S C B Medical College and Hospital, Cuttack from October 2015 to September 2017 both in outpatient department and indoor after getting Ethical committee clearance of the institution. The total cases included in our study was forty. Detailed history and clinical examination of all patients suffering from chronic liver disease was taken and haematology and liver function test were recorded. Other investigations like ultra sound, upper gastrointestinal (G I) endoscopy, viral and auto immune markers, liver biopsy were done as and when indicated.

Inclusion Criteria: The children age between 1 year to 14 years with features of chronic liver disease which includes deranged liver functions test, enlarged or shrunken liver, splenomegaly, edema, ascitis, bleeding from varices and cutaneous features like spider angiomata /palmer erythema for more than 3 months.

Exclusion Criteria: It includes a). Children below 1year and over 14 years, b). Children with haemolytic anemia, c). children with neonatal hepatitis and extrahepatic biliary atresia, d). Children suffering from HIV infection.

All cases were recorded in prescribed proforma and were subjected to routine heamotological investigations and other ancillary investigations as and when required.

\section{Methods}

1. SGOT (Serum Glutamic Oxaloacetic Transaminase) / (AST-Aspartate Aminotransferase): It is measured in serum by the method of Reitman and Frankel.

2. SGPT (Serum Glutamic Pyruvic Transaminase) (ALT - Alanine Aminotransferase): It is measured in serum by the method of Reitman and Frankel.

3. Serum Alkaline Phosphatase: its measured by King, Abdul Fade and Walker Method

4. Serum Bilirubin: It was done by Evelyn and Malloy Method.

5. Serum Protein: It was done by Biuret Method.

6. Serum Albumin: It was done by principles based on the work of Doumas, modified by Spencer and Price.

7. Prothrombin Time: It was done by Quick on stage method

8. Immunocombo HBs Ag Test: it was done by $3^{\text {rd }}$ generation Elisa Kit HBs Ag one step.

9. Micro Elisa HCV: Done by Third generation enzyme immune assay for determination of Antibodies to HCV.

10. Liver Biopsy: Done by using Tru-Cut Needle done when indicated (with parental consent)

11. Upper GI Endoscopy: Done by gastroenterologist for looking esophageal varices.

12. Slit Lamp Examination: To look for KayserFleischer Ring as an evidence of Wilson'sdisease.

The clinical, biochemical \& etiological profile were noted and analysed statistically.

\section{Observation}

Table-1: Incidence of CLD in Patients with Liver Disease.

\begin{tabular}{|c|c|c|c|c|c|c|c|c|}
\hline \multirow[t]{3}{*}{ Liver disease } & \multicolumn{6}{|c|}{ Number of patients } & \multirow[t]{3}{*}{ Total } & \multirow[t]{3}{*}{ Percentage } \\
\hline & \multicolumn{2}{|c|}{$1-5$ years } & \multicolumn{2}{|c|}{ 6-10 years } & \multicolumn{2}{|c|}{ 11-14 years } & & \\
\hline & Male & Female & Male & Female & Male & Female & & \\
\hline Chronic liver disease & 2 & - & 16 & 11 & 7 & 4 & 40 & 18.34 \\
\hline Non-CLD & 5 & 4 & 71 & 45 & 38 & 15 & 178 & 82.56 \\
\hline Total & 7 & 4 & 87 & 56 & 45 & 19 & 218 & 100 \\
\hline
\end{tabular}


During the study period, 218 patients were diagnosed with liver diseases, out of which 40 patients (18.34\%) were diagnosed with chronic liver disease and 178 (82.56\%) were diagnosed with other forms of liver disorders. The most common age group is between 5-10 years, males were more affected than female.

Table-2: Clinical Symptoms.

\begin{tabular}{|c|c|c|}
\hline Clinical Feature & Number of Patients & Percentage \\
\hline Fever & 28 & 70 \\
\hline Jaundice & 28 & 70 \\
\hline GI Bleeding & 4 & 10 \\
\hline Altered Sensorium & 2 & 5 \\
\hline
\end{tabular}

Jaundice (70\%) and fever (70\%) were the most common presentation in our study.

Table-3: Physical Findings.

\begin{tabular}{|c|c|c|}
\hline Features & Number of Patients & Percentage \\
\hline Pallor & 34 & 85 \\
\hline Icterus & 28 & 70 \\
\hline Hepatomegaly & 28 & 70 \\
\hline Splenomegaly & 19 & 47.5 \\
\hline Ascitis & 26 & 65 \\
\hline Altered Sensorium & 2 & 5 \\
\hline GI Bleeding & 4 & 10 \\
\hline
\end{tabular}

Pallor was present in 34 patients (85\%). Icterus and Hepatomegalywere present in 28 patients each (70\%). Ascites wasnotedin 26 patients $(65 \%)$, splenomegaly was found in 19 patients $(47.5 \%)$

Table-4: Serum bilirubin (total) at presentation $(\mathrm{N}=40)$

\begin{tabular}{|c|c|c|}
\hline Serum Bilirubin in mg \% & Number of patients & Percentage \\
\hline$<1$ & 2 & 5 \\
\hline $1-5$ & 15 & 37.5 \\
\hline $6-10$ & 18 & 45 \\
\hline $11-15$ & 4 & 2.5 \\
\hline $16-20$ & 1 & 10 \\
\hline
\end{tabular}

The above table shows 15 patients (42.5\%) had serum bilirubin level between $1-5 \mathrm{mg} / \mathrm{dl}$, 18 patients (45\%) had serum bilirubin between $6-10 \mathrm{mg} / \mathrm{dl}$.

Table-5: Biochemical Parameters

\begin{tabular}{|c|c|c|c|}
\hline Level in IU/L & SGPT & SGOT & Serum albumin \\
\hline$<100$ & 19 & 14 & 12 \\
\hline $100-400$ & 20 & 25 & 23 \\
\hline$>400$ & 1 & 1 & 5 \\
\hline
\end{tabular}

Nineteen (47.5\%) patients had SGPT value between 40-100IU/L. About 20 Patients (50\%) patients had SGPT between $100-400 \mathrm{IU} / \mathrm{L}$. One Patient (2.5\%) had SGPTvalue $>400 \mathrm{IU} / \mathrm{L}$.

About 14 Patients (35\%) patients had SGOTvalue $<100 \mathrm{IU} / \mathrm{L}$ at the time of presentation. About 25 patients $(62.5 \%)$ had SGOT value between 100-400 IU/L and 1 patient (2.5\%) had SGOT value $>400 \mathrm{IU} / \mathrm{L}$. 
Editorial

Table-6: Upper GI Endoscopy finding ( $=35)$

\begin{tabular}{|c|c|c|}
\hline Endoscopic Finding & Number of patients & Percentage \\
\hline Absence ofvarices & 21 & 60 \\
\hline GradeI varices & 3 & 22.85 \\
\hline GradeII Varices & 8 & 5.7 \\
\hline GradeIII Varices & 2 & 2.85 \\
\hline GradeI VVarices & 1 & 2.57 \\
\hline
\end{tabular}

In $60 \%$ of patients the endoscopic finding was normal, 22.85 patients show gradeII varices.

Table-7: Etiology of chronic liver disease

\begin{tabular}{|c|c|c|}
\hline Etiology & Number of Patients & Percentage \\
\hline Wilson's disease & 11 & 27.5 \\
\hline Budd-Chiari syndrome & 2 & 5 \\
\hline Auto immune hepatitis & 2 & 5 \\
\hline Drug induced & 2 & 2.5 \\
\hline Hepatitis $-\mathrm{C}$ & 1 & 2.5 \\
\hline Choledochal cysts & 1 & 52.5 \\
\hline Cryptogenic & 21 & $\mathbf{1 0 0}$ \\
\hline Total & $\mathbf{4 0}$ & 5 \\
\hline
\end{tabular}

Eleven patients $(27.5 \%)$ had Wilson'sdisease. In 21 patients $(52.5 \%)$ cause could not be established.

Table-8: Liver Biopsy Findings.

\begin{tabular}{|c|c|c|}
\hline Liver biopsy finding & No of patients & Percentage \\
\hline Chronic hepatitis & 17 & 73.9 \\
\hline Cirrhosis & 6 & 26.08 \\
\hline
\end{tabular}

Around 23 patients $(62.5 \%)$ out of a total of 40 patients underwent liver biopsy. Around17 patients $(73.9 \%)$ showed evidence of chronic active hepatitis and in 6 patients $(26.08 \%)$ cirrhosis was seen in the liver biopsy specimens.

\section{Discussion}

A total of 218 patients with features of liver disease attending to our hospital were thoroughly evaluated, out of which 40 patients $(18.34 \%)$ were diagnosed with chronic liver disease, these were included in our study. The most of the patients were between 5-10 years of age group. The mean age at presentation was $9.44 \pm 2.69$ years. Our study is similar tothe result reported by Ganie et al [5], 2014. About 25 patients (62.5\%) were males and 15patients(37.5\%) were females. The males out numbered females by 1.67:1. The finding in our study is similar that in studies by Akinbami et al and Hanif et al[9] but contrary to study by Ganie et al[5]

Jaundice was found in 28 patients (70\%) and fever in 28 patients $(70 \%)$ were most common presentations in our study. The other features in our study were GI bleed in 4 patients $(10 \%)$ and altered sensorium in 2 patients (5\%). The finding in our study are similar to the study by Dangwal et al. In their study they found jaundice in $70 \%$ of the cases and fever in $67 \%$ of the cases. Pallor was present in 34 patients (85\%) and was most common clinical features.

The other features were hepatomegaly in 28 patients (70\%) and icterus in 28 patients $(70 \%)$. The other features were ascitis in 26 patients (65\%), splenomegalyin 19 patients, GI Bleeding in 4 patients(10\%). This finding is similar to study done by Hanif et al [9] in which they had reported pallor to be present in $95 \%$ of the cases. 
The percentage of patients presenting with jaundice /icterus in our study is $70 \%$, which correlates with the study conducted by Hanif et al [9] and Ira Shah et al[12] who found jaundice in $67 \%$ \& $70 \%$ cases respectively.

Hepatomegaly was found in $70 \%$ of patients in our study which resembles the finding in the study by Ira Shah et al [12] and Hanif et al [9] who found hepatomegaly in $71 \% \& 64 \%$ of the case respectively. This differs from the study by Ganie et al [5] where hepatomegaly was found in only $22 \%$ of cases.

Splenomegaly was found in $47.5 \%$ of our patients similar to the finding by Ira Shah et al [12] and Dangwal et al [10]but differs from the studyby Hanif et al [9] andGanie et al [5] who reported splenomegalyin $76 \%$ and $65 \%$ of the cases respectively.

In our study, $65 \%$ of the patients had Ascites. The finding resembles the study by Dangwal et al but differs from the study by Hanif et al who reported Ascites in $84 \%$ of the case in their study. Altered sensorium was present in 2 patients $(5 \%)$ in our study out of which one patient died during course of study due to associated sepsis. Ten percentage of the patients presented with GI bleeding resembling the study by Ganie et al [5] but in a study by Hanif et al[9] GI Bleed was present in $46 \%$ of patients.

According to Leuschner $U$ [13], Serum bilirubin is normal except in severe disease. In our study hyper biliubinemia was seen in $95 \%$ of the patients. These finding correlates with the study by Hanif et al [9] in which hyperbilirubenimia was found in $90 \%$ of the patients. Directhyper bilirubemia was seen in 37 patients $(92.5 \%)$.

About $50 \%$ patients had moderate elevation in the SGPT levels. The lowest SGPT value in the series was $43 \mathrm{U} / \mathrm{L}$ and the highest value in the series was $406 \mathrm{U} / \mathrm{L}$.

Moderately increased SGOT levels was seen most commonly. It was seen in 25 patients $(62.5 \%)$. The lowest SGOT value in this series was $40 \mathrm{U} / \mathrm{L}$ and the highestvalue was $412 \mathrm{U} / \mathrm{L}$.

Serum alkaline phosphatase was increased in 33 patients $(72.5 \%)$. The highest value of Serum Alkaline phosphatase in our study was 2029 U/L. In our study 25patients $(62.5 \%)$ had moderate anemia. About 3 patients had hemoglobin less than $7 \mathrm{~g} / \mathrm{dl}$ and 12 patients $(30 \%)$ of the patients had hemoglobin more than 10 $\mathrm{g} / \mathrm{dl}$.
Prothrombin time is prolonged in $70 \%$ patients and normal in $30 \%$ of the patients. This finding is similar to the finding in the study by Hanif et al [9].

Upper GI endoscopy was done in 35 patients $(87.5 \%)$ of the patients. Out of them 21 patients $(60 \%)$ did not have any verices, whereas 14 patients $(40 \%)$ had esophageal varices suggestive of presence of portal hypertension.

Seventeen patients $(73.9 \%)$ who underwent liver biopsy had features of chronic hepatitis in their liver biopsy specimen whereas 6 patients $(26.08 \%)$ had evidence of cirrhosis. This finding in our study is similar to that of Hanif et al [9].

The most common etiology was to be found was Wilson's disease in 11 patients $(27.5 \%)$ of patients .About 2 patients $(5 \%)$ were diagnosed was Budd-Chiari syndrome and another 2 patients $(5 \%)$ were diagnosed with drug induced hepatitis. Chronic hepatitis $\mathrm{C}$ and Choledochal cyst was diagnosed in 1 Patient $(2.5 \%)$ each. No etiology was found in $52.5 \%$ of the patients.

Wilson's disease was diagnosed in $27.5 \%$ of the patients in our study. This finding resembles the findings of the study by Yachha et al [14] and Zhang et al [15]. This finding differs from the study by Hanif et al [9] in which $16 \%$ of the patients were diagnosed with Wilson's disease. About 1 patient was diagnosed with Chronic hepatitis C. No patient was diagnosed with hepatitis Binfection. This finding is in contrast to the study by Yachha et al [14], Ganie et al [5], Hanif et al[9] where hepatitis B was diagnosed in $12 \%$. $18 \%$ and $24 \%$ of the patients respectively.

In the present study autoimmune hepatitis was diagnosed in $5 \%$ of the patients. This finding is similar to the finding by Yachha et al [14] (4\%), Rafeey et al $[16](5.6 \%)$, Zhang et al [15](7\%). Other authors showed a higher incidence like Hanifetal [9] (16\%).

No etiology could be found in $52.5 \%$ of our patients. Similar finding were reported by Yachha et al [14], Rajeswariet al [17], Ganie et al [5]. This finding differs from the study by Hanif et al [9].

\section{Conclusion}

Chronic liver disease is not uncommon condition in children. It constitutes $18.34 \%$ of the patients with liver disease in our region. Wilson's disease was the most common etiology as it was found in $27.5 \%$ of the patient. No case of hepatitis B infection was found during the course of the study and ChronicHepatitis C 
was diagnosed in $2.5 \%$ of the patients. No etiology could be found in $52.5 \%$ of the patient. The high incidence of idiopathic chronic liver disease (Dar et al) [3] indicates further research needs to be done to find out other cause of liver disease. The low incidence of chronic liver disease due to Chronic Hepatitis B, wasmost probably due to good immunization coverage, screening of blood products, usage of universal precautions.

Funding: Nil, Conflict of interest: None initiated, Perission from IRB: Yes

\section{References}

1. Bhave S, Bavdekar A, Pandit A. Changing pattern of chronic liver disease (CLD) in India. Indian J Pediatr. 1994 Nov-Dec;61(6):675-82.

2. Sachin Devidas Dhole, Archana S. Kher, Radha G. Ghildiyal and Manjusha P. Tambse. Chronic Liver Diseases in Children: Clinical Profile and Histology: J Clin Diagn Res. 2015 Jul; 9(7): SC04-SC07.

3. Dar GA, Zarger SA, Jan K, Malik MI, Mir TA, Dar MA. Spectrum of Liver Diseases among Children in Kashmir Valley. Academic Medical Journal of India. 2014 Nov 20;2(3):80-6.

4. Mukherjee PS, Vishnubhatla S, Amarapurkar DN, Das K, Sood A, Chawla YK, et al. (2017) Etiology and mode of presentation of chronic liver diseases in India: A multi centric study. PLoS ONE 12(10): e0187033. https://doi. org/10.1371/journal.pone.0187033

5. Gulzar Ahmad Dar, Mohammad Ishaq Malik, Farooq Ahmad Ganie*, Kowsar Jan, Tariq Abdullah, Mohd Iqbal Dar and Maqsood Ahmad Dar; Chronic Liver Diseases in Children: Clinical Spectrum and Etiology $\mathrm{BBB}[2][2][2014] 406-411$.

6. Francesca Rinaldi, Enrico Brunetti, Andreas Neumayr, Marcello Maestri, Samuel Goblirsch, and Francesca Tamarozzi Cystic echinococcosis of the liver: A primer for hepatologists World J Hepatol. 2014 May 27; 6(5): 293-305.
7. Chaturvedi K, Vohra P. Non-alcoholic fatty liver disease in children.Indian Pediatr.2012Sep;49(9):757-8.

8. Akinbami FO, Venugopalan P, Nirmala V, Suresh J, Abiodun P. Pattern of chronic liver disease in Omani children: A clinicopathological review. West Afr J Med 2004; 23:162-6.

9. Hanif M, Raza J, Qureshi H, Issani Z. Etiology of chronicliver disease in children. J Pak MedAssoc. 2004 Mar; 54(3):119-22.

10. Dangwal T.R, Agrwal V, Malhotra V, Bavaga V and Mittal S.K. Clinical spectrum of chronic liver diseases in North India. Trop. Gastroenterol. 1997; 18 (4): 184 .

11. Hanif M, Raza J, Qureshi H, Issani Z. Etiology of chronic liver disease in children. J Pak Med Assoc. 2004 Mar;54(3):119-22.

12. Ira Shah, Susmita Bhatnagar Clinical Profile of chronic hepatobiliary disorders in children: experience from tertiary referral centre in western India Tropical Gastroenterology2010;31(2):108-110

13. Leuschner U. Primarybiliary cirrhosis--presentation and diagnosis. Clin Liver Dis. 2003 Nov;7(4):741-58.

14. Yachha SK, Sharma BC, Khanduri A, Srivastava A. Current spectrum of hepatobiliary disorders in northern India. Indian Pediatr. 1997 Oct;34(10):885-90.

15. Zhang HF, Yang XJ, Zhu SS, Zhao JM, Zhang TH, Xu ZQ, Chen DW, Wang SS, Chen JM. Pathologicalchanges and clinical manifestations of 1020 children with liver diseases confirmed by biopsy. Hepatobiliary Pancreat Dis Int. 2004 Aug;3(3):395-8.

16. Rafeey M, Kianrad M, Hasani A. Autoimmune hepatitis in Iranian children. Indian J Gastroenterol. 2007 Jan-Feb;26(1):11-3.

17. Rajeshwari K, Gogia S. The clinical spectrum of chronic liver disease in children presenting to a tertiary level teaching hospital in New Delhi. Trop Doct 2008; 38:101-102.

\section{How to cite this article?}

Behera A, Murmu M.C. A study on clinico-etiological profile of chronic liver disease in children between 1 year to 14 years of age. Int J Pediatr Res. 2018;5(1):31-36. doi:10.17511/ijpr.2018.i01.07. 